\title{
The Effects of Parents' Job Insecurity on the Subjective Well-Being of Adolescents
}

\author{
Nayin Ke \\ Management School, Ji'nan University, Guangzhou, China \\ Email: kathleenqq@126.com
}

How to cite this paper: Ke, N.Y. (2018) The Effects of Parents' Job Insecurity on the Subjective Well-Being of Adolescents. Open Journal of Business and Management, 6, 279-290.

https://doi.org/10.4236/ojbm.2018.62020

Received: March 12, 2018

Accepted: April 14, 2018

Published: April 17, 2018

Copyright (c) 2018 by author and Scientific Research Publishing Inc. This work is licensed under the Creative Commons Attribution International License (CC BY 4.0).

http://creativecommons.org/licenses/by/4.0/

\section{(c) (i) Open Access}

\begin{abstract}
Administering Teenagers perceived Parents' Job Insecurity Questionnaires and Subject Well-Being Questionnaires to the sample consisting of 281 teenagers, the paper is to explore the characteristics of teenagers' perceived parents' job insecurity and its effects on subject well-being. The results showed that: As the average score of the students in the high school and the university were both higher than the overall average, the one of the middle school students was lower. Additionally, the perceived qualitative job insecurity of fathers of the teenagers in the university was significantly higher than that of the high school and the middle school. Also, qualitative job insecurity of fathers was significant positive predictor of teenagers' negative emotion, however, job insecurity of mothers showed no significance to teenagers' emotion. Thus, there are two main conclusions: teenagers in the university worry about parents' loss of jobs more often than others in the middle and high school. Secondly, it is the qualitative job insecurity of father that causes negative effects to teenagers' subjective well-being while the effects from the job insecurity of mother is not obvious. The combination of job insecurity and subject well-being of teenagers is effective for human resource management and teenagers' mental health.
\end{abstract}

\section{Keywords}

Perceived Parents' Job Insecurity, Subject Well-Being, Teenagers

\section{Introduction}

With the rapid development of economy and its environment, the technological advances have changed the nature of a large number of original labor jobs, replacing them with machine and software. To some extents, this series of changes causes the employees in the enterprises worry about the stability of the job, the 
organization's fate, resulting in job insecurity. There are studies in the field of work and family interface research found that, the negative emotion, attitude and behaviors of the employees caused by these changes in the work would be brought to the family, affecting the process and dynamic mechanism of the life of the family [1]. Among them, the influence on the children was one of the main effects of job insecurity on the family. Thus, this paper mainly discusses the effects of the working parents' job insecurity on the young children's subjective well-being, combining two research areas of job insecurity and subject well-being.

Since the 1980s, scholars have studied job insecurity. At present, job insecurity has become an important concept in the field of organizational behavior and occupational mental health. The research on job insecurity in developed countries such as Europe and America is the majority [2]. Greenhalgh and Rosenblatt (1984) studied job insecurity first, "job insecurity is the job of the employee in a threatened scenario and a kind of powerlessness" [1]. At the same time, they point out that, in addition to the looming threat of unemployment, the threat of valuable job loss is also a non-negligible aspect [3]. This is also the earliest multi-dimensional description of job insecurity. Hellgren and Sverke (1999) also put forward the concept of job insecurity, thinking that job insecurity actually should also be a kind of subjective feeling, this feeling is based on the employee's work environment of the uncertainty of perception. On this basis, the authors put forward the job quantity insecurity and job quality insecurity [4]. The former is the employee's concern about losing the job itself, while the latter reflects the perception of the employee's threat to the quality of the employment relationship [5]. The foreign and domestic research focused on the effects of job insecurity, found that job insecurity mainly influenced on the organization, individuals and also family [6].

Diener (1984) proposed that the so-called Subject well-being was an overall evaluation of the quality of life on individuals based on self-determined criteria [7]. It included two basic components of life satisfaction and emotional experience. The former was an individual's cognitive evaluation of the overall quality of life, namely, the degree of satisfying judgment on personal life in general. The latter referred to the emotional experience in an individual's life, including positive emotions (pleasant, relaxed, etc.) and negative emotions (anxious, nervous, etc.) [8]. Roskies and Louis-Guerin'S study found that subjective job insecurity had a greater explanatory power for mental health [9]. Adolescents' psychological activities were complex, and their psychological quality had many factors, parents were the important caregivers of adolescents' mental health, and parents' emotions were often the guide lines of children's emotions. Therefore, the investigation to the adolescent awareness work insecurity, on the one hand, could enlarge the influence of staff stress management and job insecurity effect research scope. On the other hand, it also provides support for the research of the development of the adolescent mental health. 
Barling et al. suggested that children perceived father job insecurity tended to produce negative beliefs and attitudes, but the effects of mother's job insecurity was not so obvious. In addition, teenagers' perception of their parents' job insecurity was different in groups. Therefore, this paper, in addition to study the different effects of parents job insecurity on children's subject well-being differences, also focused on the respectively different categories of adolescent awareness of the differences between job insecurity. The discussion on this topic will help to make suggestions and countermeasures for the development of human resource management, family mental health and adolescent mental health.

\section{Subjects and Methods}

\subsection{Subjects}

In this paper, families consisted of father and mother and children who are studying in junior high school to college were selected as the subjects. It was sent to the teachers and the students mainly from Huaqiao University in Quanzhou, China. A total of 294 questionnaires were issued, and 281 valid questionnaires were obtained after deleting the invalid questionnaires. Considering that the young children may have difficulty in understanding the questionnaire, the survey respondents in this paper are mainly teenagers who are in their first year of middle school to senior year of university. The sample data were divided into four categories: gender, one-child, source and grade. Considering that the rural children questionnaire recovery rate might be low, and the rural parents dual-earner couples family type is less, so exclude rural students, setting from the category to towns and cities. According to the gender classification, the boys accounted for $44.8 \%$ and the girls' was $47.7 \%$. According to the classification of one-child, the one-child family accounted for $71.2 \%$, and the non-only children accounted for $20.6 \%$. According to the classification of students, $12.1 \%$ of adolescents were from rural areas and $79 \%$ of them were from urban; The ten levels of grade variables were graded according to middle school, high school and university: 70 students in junior middle school, accounting for $24.9 \%$, and 43 students in high school, accounting for $15.3 \%$, and 126 undergraduates, accounting for $44.8 \%$. The basic information of the formal survey sample is shown in Table 1.

\subsection{Tools}

This article mainly uses the parents' job insecurity questionnaire and the subject well-being questionnaire survey.

Parents job insecurity questionnaire compiled by domestic researchers $\mathrm{Hu}$ Sanman, composing of nine projects of perceived job insecurity questionnaire, dividing into the questionnaire of the qualitative job insecurity of the parents (4 items) and the questionnaire of the quantitative job insecurity of the parents (5 items). Likert 5 points scoring were used in this study, from 1 to 5 respectively representing, "very disagree", “compare disagree", "not sure”, “compare agree”, 
Table 1. The basic information of the formal survey sample.

\begin{tabular}{|c|c|c|c|c|}
\hline- & Category & Quantity & Proportion & Sum \\
\hline \multirow{3}{*}{ Gender } & Male & 126 & $44.8 \%$ & \multirow{3}{*}{281} \\
\hline & Female & 134 & $47.7 \%$ & \\
\hline & Missing Value & 21 & $7.5 \%$ & \\
\hline \multirow{3}{*}{ One-child } & Yes & 200 & $71.2 \%$ & \multirow{3}{*}{281} \\
\hline & No & 58 & $20.6 \%$ & \\
\hline & Missing Value & 23 & $8.2 \%$ & \\
\hline \multirow{3}{*}{$\begin{array}{l}\text { Source of } \\
\text { Students }\end{array}$} & Rural Areas & 34 & $12.1 \%$ & \multirow{3}{*}{281} \\
\hline & Urbans & 222 & $79 \%$ & \\
\hline & Missing Value & 25 & $8.9 \%$ & \\
\hline \multirow{4}{*}{ Grade } & Junior High School & 70 & $24.9 \%$ & \multirow{4}{*}{281} \\
\hline & Senior High School & 43 & $15.3 \%$ & \\
\hline & College & 126 & $44.8 \%$ & \\
\hline & Missing Value & 42 & $14.9 \%$ & \\
\hline
\end{tabular}

"very agree". The number of Cronbach alpha of the perceived father job insecurity in the survey questionnaire was 0.917 , while the perception to father work quality insecurity questionnaire on the number of Cronbach alpha was 0.878 , and the perception to father work quantity insecurity questionnaire on the number of Cronbach alpha was 0.928. Meanwhile, the perceived mother job insecurity in the survey questionnaire on the number of Cronbach alpha was 0.916, while the perception to mother work quality insecurity questionnaire on the number of Cronbach alpha was 0.867 , and the perception to mother work quantity insecurity questionnaire on the number of Cronbach alpha was 0.929.

The subjective well-being questionnaire adopts the practice of the research field, which is to examine the degree of subjective well-being of individuals through comprehensive life satisfaction, positive emotion and negative emotion. Among them, the life satisfaction questionnaire is from Diener's life satisfaction scale, compiled in 19855 project [10] [11] using Likert seven point scale, 1 means very inconsistent, and 7 means very consistent with it. The Cronbach coefficient of the questionnaire in this survey was 0.866 .

\subsection{Methods}

When the questionnaire was formally released, subjects were told that this was a family impact study of their parents' work experience to avoid subjective factors. After answering the questionnaire, we collect and remove the information on the spot, filled in the incomplete and invalid questionnaire, input the remaining questionnaire into the data and follow-up analysis, and produced the corresponding chart, according to the analysis of the results. A standardized empirical research method was used to analyze and verify the theoretical assumptions 
based on the data obtained from the questionnaire survey. In the process of statistical analysis, SPSS was used to carry out the frequencies analysis, the compare means analysis, the correlation analysis and the hierarchical regression analysis.

\section{Results}

\subsection{Analysis on the Differences}

This article conducted a multivariate analysis of variance on the sense of parental insecurity perceived by adolescents who participated in the survey based on gender, child-only birthplace, and education stage as independent variables. As shown in Table 2, among the test results of gender, only child and difference of provenance, the interaction effect is not significant, while the main effect of the difference test with education stage as independent variable is significant ( $P$ $<0.05)$. As can be seen from Table 2, the average scores of perceived insecurity among parents in junior high school are lower than the overall average, while the average scores of senior high school students and college students are higher than the overall average. Among them, the average scores of senses of perceived father's quality of work in college were significantly higher than those of middle school and junior middle school. As can be seen from Figure 1, the perceived insecurity of adolescent-perceived parents in junior and senior high schools shows an upward trend. All of them show turning points in the senior high school. At the university level, perceived insecurity among their adolescents was

Table 2. Average points compared.

\begin{tabular}{|c|c|c|c|c|c|}
\hline \multicolumn{2}{|c|}{ Category } & $\begin{array}{l}\text { Quantitative job } \\
\text { insecurity of fathers }\end{array}$ & $\begin{array}{c}\text { Qualitative job } \\
\text { insecurity of } \\
\text { fathers }\end{array}$ & $\begin{array}{c}\text { Quantitative job } \\
\text { insecurity of } \\
\text { mothers }\end{array}$ & $\begin{array}{c}\text { Qualitative job } \\
\text { insecurity of } \\
\text { fathers }\end{array}$ \\
\hline \multicolumn{2}{|c|}{ Sum } & $2.07(1.04)$ & $2.58(1.01)$ & $2.09(1.03)$ & $2.50(0.94)$ \\
\hline \multirow{3}{*}{ Gender } & Male & $2.18(1.04)$ & $2.69(1.00)$ & $2.21(1.07)$ & $2.55(0.89)$ \\
\hline & Female & $1.98(1.11)$ & $2.47(1.07)$ & $1.97(1.05)$ & $2.45(1.04)$ \\
\hline & $\mathrm{F}$ & 1.22 & 1.56 & 1.80 & 0.43 \\
\hline \multirow{3}{*}{ One-child } & Yes & $2.08(1.10)$ & $2.63(1.02)$ & $2.13(1.13)$ & $2.56(0.98)$ \\
\hline & No & $2.10(1.03)$ & $2.38(1.10)$ & $2.00(0.82)$ & $2.29(0.94)$ \\
\hline & $\mathrm{F}$ & 0.14 & 1.40 & 0.67 & 1.85 \\
\hline \multirow{3}{*}{$\begin{array}{l}\text { Source of } \\
\text { Students }\end{array}$} & Urbans & $2.44(1.02)$ & $2.77(1.07)$ & $2.26(0.88)$ & $2.48(0.84)$ \\
\hline & Rural Areas & $2.01(1.07)$ & $2.54(1.03)$ & $2.04(1.08)$ & 2.49 (0.99) \\
\hline & $\mathrm{F}$ & 2.63 & 0.79 & 0.35 & 0.77 \\
\hline \multirow{5}{*}{ Grade } & School & $1.81(1.10)$ & $2.34(1.12)$ & $2.01(1.18)$ & $2.46(1.11)$ \\
\hline & Senior & & & & \\
\hline & High & $2.23(1.07)$ & $2.61(0.91)$ & $2.10(0.98)$ & $2.68(0.91)$ \\
\hline & College & $2.14(1.07)$ & $2.72(0.97)$ & $2.12(0.99)$ & $2.53(0.88)$ \\
\hline & $\mathrm{F}$ & 2.89 & $3.30^{*}$ & 0.23 & 0.72 \\
\hline
\end{tabular}

a. ${ }^{*} P<0.05,{ }^{*} P<0.01$, the same below. 


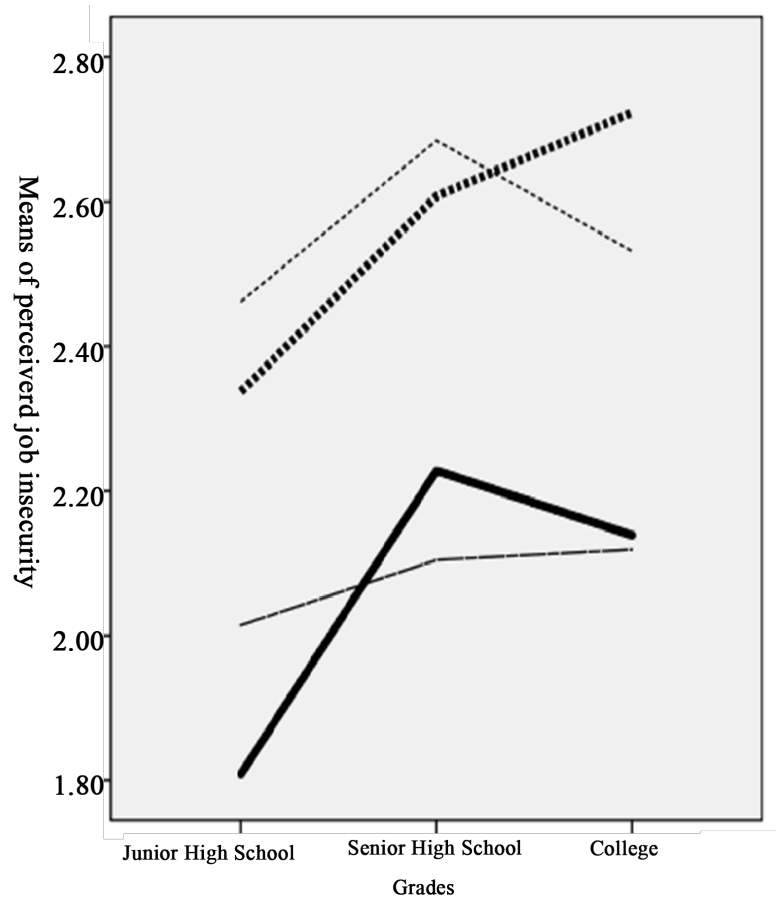

Quantitative job insecurity of fathers III. Qualitative job insecurity of fathers - Quantitative job insecurity of mothers ...- Qualitative job insecurity of mothers

Figure 1. Means comparison.

significantly higher than that of their parents' other dimensions of job insecurity score.

\subsection{Correlation Analysis}

Table 3 shows the correlation between parental insecurity and the subjective well-being of adolescents surveyed. As can be seen from Table 3, most of the relevant directions are in line with the expectation. There was a significant positive correlation between the Quantitative job insecurity of fathers and the negative emotions of adolescents. The qualitative job insecurity of fathers was positively correlated with the negative emotions of adolescents and negatively correlated with the positive emotions and life satisfaction of adolescents. However, there was a significant positive correlation between the Quantitative and qualitative job insecurity of mothers and adolescent negative emotions. The above results initially show that the higher the sense of parental insecurity, the more obvious the negative emotions of adolescents.

\subsection{Hierarchical Regression Analysis}

In order to exclude the impact of some demographic variables, further examining the specific impact of different dimensions of parental job insecurity on the three dimensions of subjective well-being, the following hierarchical regression analysis was conducted. Gender, whether one-child, grade and source of students and other demographic variables were put into the first layer for regression analysis, while the parents' job insecurity was put into the second layer.

From the results of Table 4, we can see that after excluding the influence of 
Table 3. Correlation analysis $(\mathrm{x} \pm \mathrm{s})$.

\begin{tabular}{|c|c|c|c|c|c|c|c|}
\hline Variables & $\mathrm{x} \pm \mathrm{s}$ & 1 & 2 & 3 & 4 & 5 & 6 \\
\hline 1 Quantitative job insecurity of fathers & $2.07 \pm 1.04$ & - & & & & & \\
\hline 2 Qualitative job insecurity of fathers & $2.58 \pm 1.010$ & $.622^{* *}$ & - & & & & \\
\hline 3 Quantitative job insecurity of mothers & $2.09 \pm 1.03 C$ & $.732^{* *}$ & $0.463^{\star *}$ & - & & & \\
\hline 4 Qualitative job insecurity of mothers & $2.50 \pm 0.940$ & $.517^{* *}$ & $0.666^{* *}$ & $0.642^{* *}$ & - & & \\
\hline 5 Positive emotions & $3.19 \pm 0.77$ & -0.115 & $-0.163^{* *}$ & * 0.004 & -0.041 & - & \\
\hline 6 Negative emotions & $1.79 \pm 0.77 c$ & $.166^{* *}$ & $0.211^{\star *}$ & $0.184^{* *}$ & ${ }^{\star} 0.164^{* *}$ & -0.079 & - \\
\hline 7 Life satisfaction & $4.30 \pm 1.20$ & -0.036 & $-0.140^{*}$ & 0.007 & -0.097 & $0.498^{\star *}$ & $-0.034-$ \\
\hline
\end{tabular}

Table 4. Hierarchical regression analysis.

\begin{tabular}{|c|c|c|c|c|}
\hline & Steps & Positive emotions & $\begin{array}{l}\text { Negative } \\
\text { emotions }\end{array}$ & Life satisfaction \\
\hline Step 1 & Gender & 0.004 & 0.032 & -0.035 \\
\hline & One-child & -0.012 & -0.076 & -0.033 \\
\hline & Grades & -0.028 & 0.008 & $-0.185^{\star *}$ \\
\hline & Rural areas & -0.287 & 0.076 & $-0.356^{*}$ \\
\hline & Urbans & -0.185 & -0.039 & 0.291 \\
\hline$R^{2}$ & & 0.025 & 0.015 & $0.061^{*}$ \\
\hline Step 2 & Quantitative job insecurity of fathers & -0.137 & -0.046 & 0.001 \\
\hline & Qualitative job insecurity of fathers & -0.191 & $0.220^{*}$ & -0.160 \\
\hline & Quantitative job insecurity of mothers & 0.190 & 0.147 & 0.185 \\
\hline & Qualitative job insecurity of mothers & 0.059 & -0.043 & -0.128 \\
\hline$\Delta R^{2}$ & & $0.044^{*}$ & $0.061^{\star *}$ & $0.046^{*}$ \\
\hline
\end{tabular}

demographic variables, the qualitative job insecurity of fathers has a significant positive predictive value $(\mathrm{P}<0.05)$ on the negative emotions of adolescents.

\section{Suggestions and Conclusions}

\subsection{Analysis of the Results}

Above all, the present study shows that there is no significant difference in perceived differences in gender, child-only or source of students insecurity in parental work. However, from the classification of educational stages, the average scores of underemployment perceived father's quality in college are significantly higher than those of middle school and junior high school. Thus, there is no significant difference between boys and girls in perception of parental job insecurity. The only children's sense of parental job insecurity is not much different from that has brothers or sisters. Although there are differences in the family economic situation and money outlook of teenagers from urban and rural areas, 
it did not cause significant differences in perceived insecurity among their parents. Compared with teenagers in senior high school and junior high school, college students are more worried about their father's quality of working relationship. First of all, as adolescents enter the university stage, the pace of their mental development is accelerating. Some young people even hope that they can work independently from this and being independent in their minds and economy, alleviating the burden on their parents. Therefore, the independence of college students is more obvious. They are more initiative, thinking more about the issue of social surviving, so as to better understand and digest the emotion and experience of their parents' work. Once their parents show concern and anxiety about the quality of the work relationship during their family communication, especially as father is often the economic pillar of every family in China, children can make inferences based on their own experience and knowledge. Second, the environment of a university is like a microcosmic society. Some college students also know more about the workplace through their professional courses or internships. Instead of focusing on books, they have a subjective understanding of the remuneration, career development, job performance and interpersonal relationships. In contrast, adolescents of junior and senior middle school are in the relatively regular and stable environment, thinking more about their current academic and future studies, paying less attention to their parents' work, thus the quality of their father's working relationship may fail to cause too much attention.

The results also show that excluding the effects of demographic variables, qualitative job insecurity of father has a significant positive predictive effect on adolescent negative emotions, while the mothers' job insecurity has no significant effect on adolescent affectivity. Children who perceive their father's insecure job tend to have negative beliefs and attitudes towards work [12]. Despite its relevance, the impact of mother's job insecurity on children is less pronounced. This shows that the role of men and women in the family of China in the past still has a more or less influence on the thinking of young people today. Men were always given more power and responsibility, and they often play the vital role in the family. When a father shows uneasy feelings or behavior that about losing his job, children will probably over-guess and fantasize about it, raising questions about the next step of their father, like, whether his father will be cut wages or not, whether their own study will be affected, etc., resulting in mental stress and negative emotions. In addition, the higher children have the sense of identity with their father, the more negative emotions and the less subjective sense of happiness they have. As for their mothers, children are more closely related to the guardianship and communication. Some families even define the work of their mothers as a minor supplement to their father's work. Therefore, though their mothers are feeling work-insecure, their children will not amplify them and will not excessively relate to their own development and thus will not significantly affect their own subjective well-being. 


\subsection{Suggestions}

Based on the existing researches, the sense of insecurity of employees is a common conception of employees' psychological features in business organizations under different cultural backgrounds [10]. Job insecurity is a product of development and competition, reflecting the organization of the time. The environment in which individuals are employed is tense, ever-changing and volatile. The growth of the problem of job insecurity will have a negative impact on people's social attitudes. However, from the perspective of research on the consequences, job insecurity may have a potential impact on the psychology and behavior of families, especially children. Additionally, the research shows that children also experience cognitive difficulties and decreased academic performance [1]. Therefore, this article will put forward the corresponding management countermeasures and suggestions from the perspective of the impact of job insecurity on the family and the subjective sense of happiness of adolescents.

\subsubsection{Management Countermeasures to Job Insecurity Impact on Family} First, from the enterprise point of view, in the process of human resource management in enterprises, we should first manage the staff psychology scientifically and introduce EAP service. Employee Assistance Programs (EAPs) are a set of systematic and long-term benefits and support programs for employees that focus on providing personal and psychological attention to employees in an enterprise or organization. It provides healthy services to improve their personal quality of life and work performance, so that the employees can benefit individuals and organizations. EAP implementation methods include three preventive measures, the elimination of the source of the problem, education and training, staff counseling. Enterprises should attach importance to the psychological characteristics of the job insecurity of staff. Take appropriate management measures to take the initiative to control or affect staff, to reduce work insecurity by training and psychological counseling. In addition, enterprises should clarify the ladder of employee competency development and promotion. They should inform employees before they start to work, reducing the confusion and helplessness of employees in their own development, and clearly defining their own positions and goals. Moreover, it is necessary to establish a good performance appraisal system and organize it appropriately, which is conducive to an active working atmosphere and promotion of employees' feelings, avoiding the vicious competition among employees; paying attention to the tendency of leaving the company, listening to the employees' demands, and giving them scientific advice [12].

Second, employees themselves should pay attention to the work-family conflicts. Work-family conflict refers to a type of role conflict that arises when pressures from work and family are in some unmanageably contradictory. Due to work tasks or work needs, work-family conflicts make it hard for individuals to fulfill their responsibilities to families. The study found that work-family conflict is more predictive of work stress and job satisfaction than family-work con- 
flict [13]. Therefore, it is necessary to reduce work-family conflicts so as to experience the joy of work and family life, also, to reduce the insecurity accordingly. Meanwhile, the employees should improve their personal skills, because the emergence of job insecurity is often the lack of confidence in the staff to their own, when compared with others horizontally, they feel that they will be eliminated in some aspects of others. At the same time, employees should envisage their own job insecurities. In recent years, the scholars have argued that job insecurity may also serve as a source of motivation to push the employees to work harder and respond to threats at work because the employees believe good job performance will reduce their risk of being laid off. Therefore, individuals should actively respond to issues such as the relations with their workmates, personal career development and job performance by improving their personal initiative, rationally controlling negative emotions, expressing unease and doubt during their work. Also, during their family communications, parents should avoid making negative predictions to their children, and, they should pay attention to the psychological activities of their young children, encouraging them to express their doubts, and regularly sending positive messages to their children and stabilizing their confidence. For children who entered the university stage, parents should instill objective workplace information in them so as to prevent young people from creating unnecessary worries and unilateral thoughts before they enter the society.

\subsubsection{Management Countermeasures to the Subjective Well-Being of Adolescents}

There are so many factors that affect the subjective well-being of young people. The scholars summarized them into two aspects: First, external factors, such as life events, family factors, peer relationships, learning life; the other hand, internal factors, like personality traits, internal or external control tendencies, self-esteem factors, etc. Therefore, this article argues that parents should first give their families enough care. The family has a significant influence on children's subjective well-being. Parents should correctly guide the formation of children's values, concerning their emotional changes, and paying attention to their emotional abnormalities. Subjective well-being consists of three dimensions: positive emotion, negative emotion and life satisfaction. Thus, parents can target to stimulate positive emotions and life satisfaction of their children, for example, through reasonable recognition and praise, appropriate material incentives, family activities, festivals or other ways. At the same time, parents should pay attention to their own behavior in front of children. Avoid using harsh words on their children, which cares much about the adolescents' self-esteem. These words may cause negative emotions in children and may not be alleviated for a long time, leaving a psychological shadow in the children's heart.

Second, in view of the internal factors affecting the subjective well-being of adolescents, the society, schools and families should give adolescents scientific 
and healthy education. Public opinion and the mass media should guide young people to establish correct values and avoid misleading adolescents from the extreme, radical and erroneous views. Schools are where the adolescents most frequently exposed in. Meanwhile, the teachers and their classmates are also very influential on them. Schools should therefore teach them correct interpersonal approach and standardized mental health education, while avoiding the extreme phenomenon of school groups.

\subsection{Conclusions}

Based on the whole passage, there are some prospects for the study. First, this article uses a multidimensional perspective to explore job insecurity, however, the study of the effect of parental job insecurity on the subjective well-being of adolescents is largely horizontal. So, the longitudinal study of the job insecurity should be proposed in the future. Secondly, this article uses Hu Sanman, which is adopted or restructured by many scholars in China, based on the actual situation of Chinese employees to develop the scale of job insecurity. However, considering the research in this field, it is still necessary to develop a unified measurement tool of validity and reliability in the future. Thirdly, the application study of the job insecurity should be concerned. It should involve a broader scope and more specific applications for the future research on job insecurity. Fourthly, at present, most of the domestic research focus on the impact of subjective well-being of adolescents, but the subjective well-being of young people intervention research areas still needs to be developed. This article only made a simple measurement and presentation of the impact of job insecurity on the subjective well-being of adolescents. In fact, how to raise the subjective well-being of adolescents is also "a thought-provoking topic". Thus, the intervention research of the subjective well-being of adolescents should be studied deeply.

Although research on job insecurity and subjective well-being has yielded corresponding results in terms of theoretical connotation, measurement and impact effects, it is still necessary for researchers to conduct in-depth discussions in order to reduce the negative impact of job insecurity on production and life, the negative emotions, and the inhibition of subjective well-being. At the same time, hopefully, it can provide reference for the stress management of employees, other prominent topics in the mental health of workers, so as to optimize the social and organizational effectiveness of individuals.

\section{References}

[1] Sanman, H. (2007) Review of Job Insecurity. Advances in Psychological Science, 6, 938-947.

[2] Zhang, G.Y. and Qian, D. (2013) Impact of Job Insecurity on the Psychology and Behavior of Employees. Studies of Psychology and Behavior, 2, 235-238.

[3] Hu S. (2011) Impact of Job Insecurity on Job Involvement and Life Satisfaction. China Journal of Health Psychology, 19, 47-49. 
[4] Hellgren, J., Sverke, M. and Isaksson, K. (1999) A Two-Dimensional Approach to Job Insecurity: Consequences for Employee Attitudes and Well-Being. European Journal of Work and Organizational Psychology, 2, 179-195. https://doi.org/10.1080/135943299398311

[5] Tong, Z. (2011) Study of the Impact of Job Insecurity on Voice Behavior: The Mediation Role of Organizational Commitment and the Moderation Role of Procedural Justice. Zhejiang University, Hangzhou.

[6] Jiang, T.T. and Chen, J.C. (2011) Review of the Impact of Job Insecurity. Human Resource Management, No. 7, 17-20.

[7] Diener, E. (1984) Subjective Well-Being. Psychological Bulletin, 3, 542-575. https://doi.org/10.1037/0033-2909.95.3.542

[8] Zeng, J. (2008) Review of the Subjective Well-Being. Journal of Xian Politics Institute, 21, 55-59.

[9] Roskies, E. and Louis-Guerin, C. (1990) Job Insecurity in Managers: Antecedents and Consequences. Journal of Organizational Behavior, 11, 345-359. https://doi.org/10.1002/job.4030110503

[10] Cui, X.P. and Song, Z.Y. (2013) The Study of Job Insecurity and the Inspiration to Human Resource Management. Guide to Business, No. 2, 187-188.

[11] Diener, E., Emmons, R.A., Larsen, R.J. and Griffin, S. (1985) The Satisfaction with Life Scale. Journal of Personality Assessment, 49, 71-75.

https://doi.org/10.1207/s15327752jpa4901_13

[12] Barling, J., Dupre, K.E. and Hepburn, C.G. (1998) Effects of Parents' Job Insecurity on Children's Work Beliefs and Attitudes. Journal of Applied Psychology, 83, 112-118. https://doi.org/10.1037/0021-9010.83.1.112

[13] Qiu, L., Zheng, X. and Wang, Y.F. (2008) The Revision of PANAS. Chinese Journal of Applied Psychology, No. 3, 249-254. 